\title{
Short communication: Discrimination between retail bovine milks with different fat contents using chemometrics and fatty acid profiling
}

\author{
Einar Vargas-Bello-Pérez, ${ }^{11}$ Paula Toro-Mujica, ${ }^{*}$ Daniel Enriquez-Hidalgo, ${ }^{*}$ María Angélica Fellenberg, ${ }^{*}$ \\ and Pilar Gómez-Cortés† \\ *Departamento de Ciencias Animales, Facultad de Agronomía e Ingeniería Forestal, Pontificia Universidad Católica de Chile, Santiago, \\ Casilla 306, C.P. 6904411 , Chile \\ †Instituto de Investigación en Ciencias de la Alimentación (CSIC-UAM), Universidad Autónoma de Madrid, Nicolás Cabrera 9, Madrid, \\ 28049, Spain
}

\section{ABSTRACT}

We used a multivariate chemometric approach to differentiate or associate retail bovine milks with different fat contents and non-dairy beverages, using fatty acid profiles and statistical analysis. We collected samples of bovine milk (whole, semi-skim, and skim; $\mathrm{n}=62$ ) and non-dairy beverages $(\mathrm{n}=27)$, and we analyzed them using gas-liquid chromatography. Principal component analysis of the fatty acid data yielded 3 significant principal components, which accounted for $72 \%$ of the total variance in the data set. Principal component 1 was related to saturated fatty acids (C4:0, C6:0, C8:0, C12:0, C14:0, C17:0, and C18:0) and monounsaturated fatty acids (C14:1 cis-9, C16:1 cis-9, C17:1 cis-9, and C18:1 trans-11); whole milk samples were clearly differentiated from the rest using this principal component. Principal component 2 differentiated semi-skim milk samples by n-3 fatty acid content (C20:3n-3, C20:5n-3, and C22:6n-3). Principal component 3 was related to $\mathrm{C} 18: 2$ trans-9,trans-12 and $\mathrm{C} 20: 4 \mathrm{n}-6$, and its lower scores were observed in skim milk and non-dairy beverages. A cluster analysis yielded 3 groups: group 1 consisted of only whole milk samples, group 2 was represented mainly by semi-skim milks, and group 3 included skim milk and non-dairy beverages. Overall, the present study showed that a multivariate chemometric approach is a useful tool for differentiating or associating retail bovine milks and non-dairy beverages using their fatty acid profile.

Key words: fatty acid composition, gas chromatography-flame ionization detection, milk, principal component analysis

Received December 2, 2016

Accepted February 26, 2017.

${ }^{1}$ Corresponding author: evargasb@uc.cl

\section{Short Communication}

Milk and dairy products contribute significantly to the intake of high-quality proteins, micronutrients, and numerous bioactive compounds, and their inclusion in a healthy balanced diet is highly recommended (Green et al., 2015). Bovine milk fat also contains fatty acids (FA) such as C18:1 trans-11, C18:2 cis-9,trans-11, and short-chain SFA as C4:0 that may have beneficial effects for human health (O'Donnell-Megaro et al., 2011).

Consumers are increasingly concerned about the nutritional quality of dairy products (Kliem and Shingfield, 2016). In particular, lactose intolerance and the relatively high SFA content of bovine milk have driven the development and production of non-dairy beverages as alternatives (Prado et al., 2008). These products are manufactured from cereals and oilseeds such as soy, rice, almond, and cashew, among others. Non-dairy beverages are consumed worldwide, but official or scientific information is lacking about their lipid quality. The FA profile of non-dairy beverages depends mainly on the raw material used to make them, and distinct FA compositions can affect their flavor ( $\mathrm{Li}$ et al., 2015) and stability (Yang et al., 2015). Furthermore, the nutritional quality of grains is inferior compared to bovine milk because of their lower protein content, deficiency in certain essential amino acids (lysine), low starch availability, and coarse nature (Rivera-Espinoza and Gallardo-Navarro, 2010). In the last decade, world milk production and demand have increased by more than 25\% (IFCN Dairy Network, 2016). Researchers, the dairy industry, and international authorities are challenged with improving compliance and safety regulations to ensure milk safety and quality (Azcarate et al., 2017).

Chemometrics is the combined study of mathematical, statistical, and other logic-based approaches to manage and interpret chemically derived data (Shin et al., 2012). Principal component analysis, in conjunction with cluster analyses, is a common multivariate 
chemometric methodology that can be used to identify patterns and explain data similarities and differences (Kim et al., 2014). Fatty acid profiling is an important tool that offers information about the nutritional quality of dairy products (O'Donnell-Megaro et al., 2011). This information can be used for nutritional guidelines, or even to develop new dairy products with specific FA profiles. Furthermore, FA profiling could improve the quality control of food products, prevent adulteration, and ensure nutritional quality monitoring (Uncu et al., 2017). In this study, we used a method for differentiating or associating retail bovine milks with different fat contents and non-dairy beverages by characterizing the FA profiles using a gas chromatography-flame ionization detector (GC-FID) method and a multivariate chemometric methodology.

We acquired bovine milks $(\mathrm{n}=62)$ and non-dairy beverages $(n=27)$ from local supermarkets in Santiago de Chile, Chile. The sampling method was intended to provide a rich and diverse set of samples and obtain the most suitable characterization and comparison of retail bovine milks compared with non-dairy beverages. All bovine milk samples were UHT-pasteurized and categorized by total fat content: whole $=3.1 \mathrm{~g} / 100 \mathrm{~mL}$; semi-skim $=1.5 \mathrm{~g} / 100 \mathrm{~mL}$; and skim $=<0.5 \mathrm{~g} / 100 \mathrm{~mL}$. Retail bovine milk samples consisted of whole $(\mathrm{n}=8)$, semi-skim $(\mathrm{n}=8)$, flavored semi-skim $(\mathrm{n}=15)$, skim ( $\mathrm{n}$ $=17)$, and flavored skim $(\mathrm{n}=14)$. Non-dairy beverages consisted of soybean $(\mathrm{n}=11)$, almond $(\mathrm{n}=5)$, rice $(\mathrm{n}$ $=3)$, spelt wheat $(\mathrm{n}=1)$, coconut $(\mathrm{n}=3)$, rice and coconut $(\mathrm{n}=1)$, rice and almond $(\mathrm{n}=1)$, hazelnut $(\mathrm{n}=1)$, and cashew $(\mathrm{n}=1)$. We purchased 1-L Tetra Paks of each beverage (between March and April; fall season) and stored them at room temperature. We took 3 aliquots (300 $\mathrm{mL}$ each) from each package and stored them frozen at $-20^{\circ} \mathrm{C}$ until FA analysis.

Lipids from retail bovine milk and non-dairy beverages were extracted with chloroform/methanol (1:2, vol/ vol) following the Bligh and Dyer method (Bligh and Dyer, 1959). Milk triglycerides were methylated (transesterified with sodium methoxide) according to the method of Christie (1982). All chemicals and solvents were of analytical grade. We used a GC-FID system (GC-2010; Shimadzu Scientific Instruments, Columbia, MD) equipped with a 100-m column $(100 \mathrm{~m} \times 0.32$ $\mathrm{mm} \times 0.20 \mu \mathrm{m}$; Restek, Bellefonte, PA). The initial oven temperature was $110^{\circ} \mathrm{C}$, and after $4 \mathrm{~min}$, it was raised by $5^{\circ} \mathrm{C} / \mathrm{min}$ to $160^{\circ} \mathrm{C}$ and held for $10 \mathrm{~min}$. The temperature was then increased to $225^{\circ} \mathrm{C}$ at $3^{\circ} \mathrm{C} / \mathrm{min}$ and held for $10 \mathrm{~min}$, and finally increased to $240^{\circ} \mathrm{C}$ at $3^{\circ} \mathrm{C} / \mathrm{min}$. The inlet and flame-ionization detector were set at $260^{\circ} \mathrm{C}$, the split ratio was $15: 1$, and the injection volume was $2 \mu \mathrm{L}$. Hydrogen was the carrier gas at a flow rate of $25 \mathrm{~mL} / \mathrm{min}$, airflow was $400 \mathrm{~mL} / \mathrm{min}$, and the flow of nitrogen makeup gas was $40 \mathrm{~mL} / \mathrm{min}$. Fatty acid gas chromatography peaks were quantified using C19:0 as an internal standard and identified using a FA methyl ester standard mixture (37-component FAME mix; Supelco, Bellefonte, PA) and individual reference standards for C18:1 trans-11, C18:2 cis-9,trans-11, C20:5n-3, and C22:6n-3 (Nu-Chek Prep Inc., Elysian, $\mathrm{MN})$.

To determine statistical differences among milk FA (whole, semi-skim, and skim bovine milks and nondairy beverages), we performed ANOVA and multiple means comparison using Tukey's honest significant difference test. A probability of $P<0.05$ was used to determine significant differences between means. Then, we carried out a multivariate analysis to differentiate the FA profiles of retail bovine milks and non-dairy beverages. The analysis included a correlation matrix, a factorial analysis by principal component analysis, and a cluster analysis. The correlation matrix between individual FA was used to discard FA that showed high correlations $(\mathrm{r}>0.9)$ and FA without correlations. We applied Bartlett's test of sphericity to examine the hypothesis that the variables were uncorrelated, and we used the Kaiser-Meyer-Olkin index to measure sampling adequacy with factorial analysis. We also performed hierarchical clustering analysis and used a discriminant analysis to verify the extent to which samples were correctly assigned to the clusters identified in the previous analysis (Table 1). We used SPSS statistical software for Windows (version 15.0.0; SPSS Inc., Chicago IL).

The FA composition across all milk samples is presented in Table 2. Flavored milks (chocolate, vanilla,

Table 1. Principal components related to the fatty acid profile of retail bovine milks $(\mathrm{n}=62)$ and non-dairy beverages $(\mathrm{n}=23)$

\begin{tabular}{lclc}
\hline $\begin{array}{l}\text { Principal } \\
\text { component }\end{array}$ & Eigenvalue & Variable & Correlation \\
\hline 1 & 9.79 & C4:0 & 0.818 \\
& $54.43^{1}$ & C6:0 & 0.959 \\
& $(54.43)^{2}$ & C8:0 & 0.953 \\
& & C12:0 & 0.925 \\
& & C14:0 & 0.937 \\
& & C14:1 cis-9 & 0.658 \\
& & C16:1 cis-9 & 0.891 \\
& & C17:1 cis-9 & 0.810 \\
& & C18:0 & 0.727 \\
& & C18:1 trans-11 & 0.781 \\
& 1.92 & C20:3n-6 & 0.631 \\
& & C20:3n-3 & 0.941 \\
3 & $(65.67$ & C20:5n-3 & 0.767 \\
& & C22:6n-3 & 0.638 \\
& 1.21 & C18:2 trans- 9, trans- 12 & 0.226 \\
& 6.74 & C20:4n-6 & 0.592 \\
& & & 0.398 \\
\hline
\end{tabular}

${ }^{1}$ Proportion of variance explained.

${ }^{2}$ Variance accumulated. 
Table 2. Fatty acid composition (mean $\pm \mathrm{SE}$ ) of retail bovine milks and non-dairy beverages (g/L)

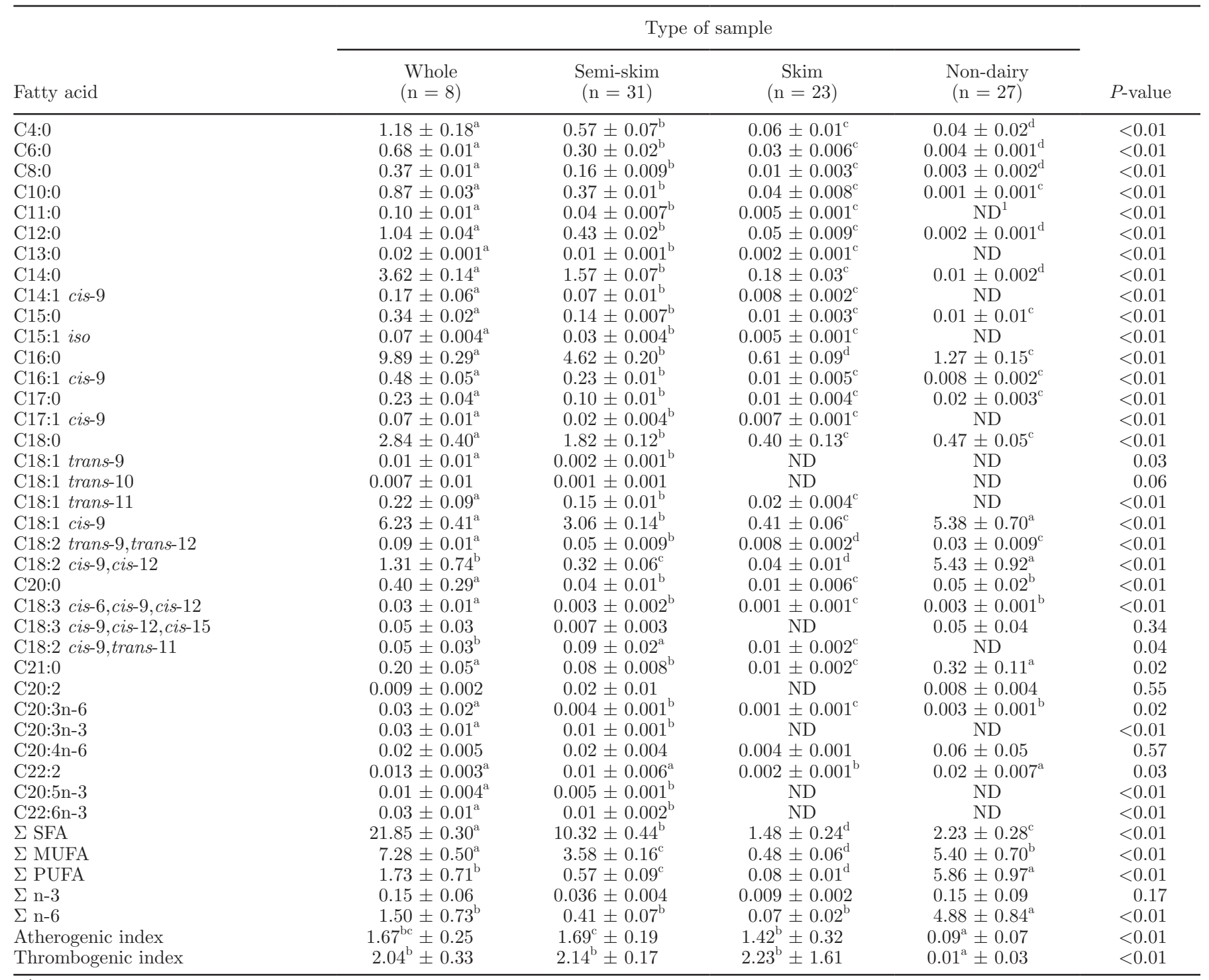

${ }^{\mathrm{a}-\mathrm{d}}$ Means with the same letter were not significantly different at $P<0.05$.

${ }^{1} \mathrm{ND}=$ not detected or $<0.001 \mathrm{~g} / \mathrm{L}$.

strawberry, banana, blackberry, apricot, and cappuccino) had FA profiles that were similar to unflavored milk (data not shown), so these milk samples were arranged according to fat content. We carried out a multivariate analysis on milk FA levels $(\mathrm{g} / \mathrm{L})$ to differentiate or associate bovine milks and non-dairy beverages. Out of the initial $36 \mathrm{FA}$ quantified, the correlation matrix allowed us to eliminate $18 \mathrm{FA}$ due to very high or very low correlations (Table 1$)$. An initial factorial analysis showed that coconut samples $(\mathrm{n}=4)$ had to be eliminated because they presented very high concentrations of C12:0 and C14:0, which were considerably different from the rest of non-dairy beverages. Once these samples were excluded, the Kaiser-Meyer-Olkin index was 0.85 and Bartlett's chi-square test was highly significant $(P<0.001)$, indicating the adequacy of the correlation matrix for subsequent factorial analysis.

Three principal components (PC) were selected from the factorial analysis and explained $72 \%$ of the overall variance [PC 1 (54\%), PC 2 (11\%), and PC $3(7 \%)]$. We found that PC 1 differentiated the whole milk samples based on their SFA (C4:0, C6:0, C8:0, C12:0, C14:0, C17:0, and C18:0) and MUFA (C14:1 cis-9, C16:1 cis-9, C17:1 cis-9, and C18:1 trans-11) levels (Table 1 ). The total SFA and MUFA contents of bovine milk fat were approximately $70 \mathrm{~g} / 100 \mathrm{~g}$ and $25 \mathrm{~g} / 100 \mathrm{~g}$, respectively, similar to reported values (O'Donnell-Megaro et al., 2011; Chung et al., 2016). Public health concerns about 
SFA come from positive correlations between their intake and cardiovascular disease risk (Eilander et al., 2015). However, although milk fat is relatively high in SFA, recent research has indicated that milk consumption does not increase cardiovascular risk (Haug et al., 2007; Visioli and Strata, 2014). For MUFA, dairy milk fat is characterized by FA with double bonds at different positions because of either ruminal biohydrogenation of dietary PUFA or $\Delta^{9}$-desaturation in the mammary gland (Kliem and Shingfield, 2016). Thus, those FA differentiated the bovine whole milk samples along PC 1 (Figure 1). It is important to mention that ruminants can synthesize C18:2 cis-9,trans-11 (which has been reported to be beneficial for human health) via $\Delta^{9}$-desaturase from C18:1 trans-11 (Kliem and Shingfield, 2016).

In contrast, semi-skim milk samples showed an intermediate position along PC 2 (Figure 1). The differentiation of these bovine milks by n-3 FA (C20:3n-3, C20:5n-3, and C22:6n-3, Table 1) could be related to the creaming process (Fauquant et al., 2005). The n-3 PUFA present low melting points because of their mul- tiple double bonds and may remain dissolved without solidifying during cream separation (Knothe and Dunn, 2009). Concentration of n-3 FA was higher in whole milk than in semi-skim milk but negligible in skim and non-dairy beverages (Table 2). The n-3 PUFA, especially C20:5n-3 and C22:6n-3, have positive effects on human health (Vestland et al., 2016), and reducing the $n-6 / n-3$ ratio of dietary PUFA intake may prevent coronary heart disease (Harris, 2008). Finally, PC 3 was related to $\mathrm{C} 18: 2$ trans-9,trans- 12 and $\mathrm{C} 20: 4 \mathrm{n}-6$, and lower scores were associated with samples that had a low amount of fat $(<1 \mathrm{~g} / 100 \mathrm{~mL})$, namely skim milk and non-dairy samples.

Based on each FA profile, we used cluster analysis to categorize the samples into 3 groups (Figure 1). The discriminant analysis correctly assigned $98 \%$ of the samples. Bovine skim milk and non-dairy beverages were not separated by the cluster analysis (Table 2 ). Non-dairy beverages were defined by higher C18:1 cis-9, C18:2 cis-9,cis-12, total MUFA, and total PUFA contents compared with skim milk samples. However, the FA profile of non-dairy beverages may differ greatly

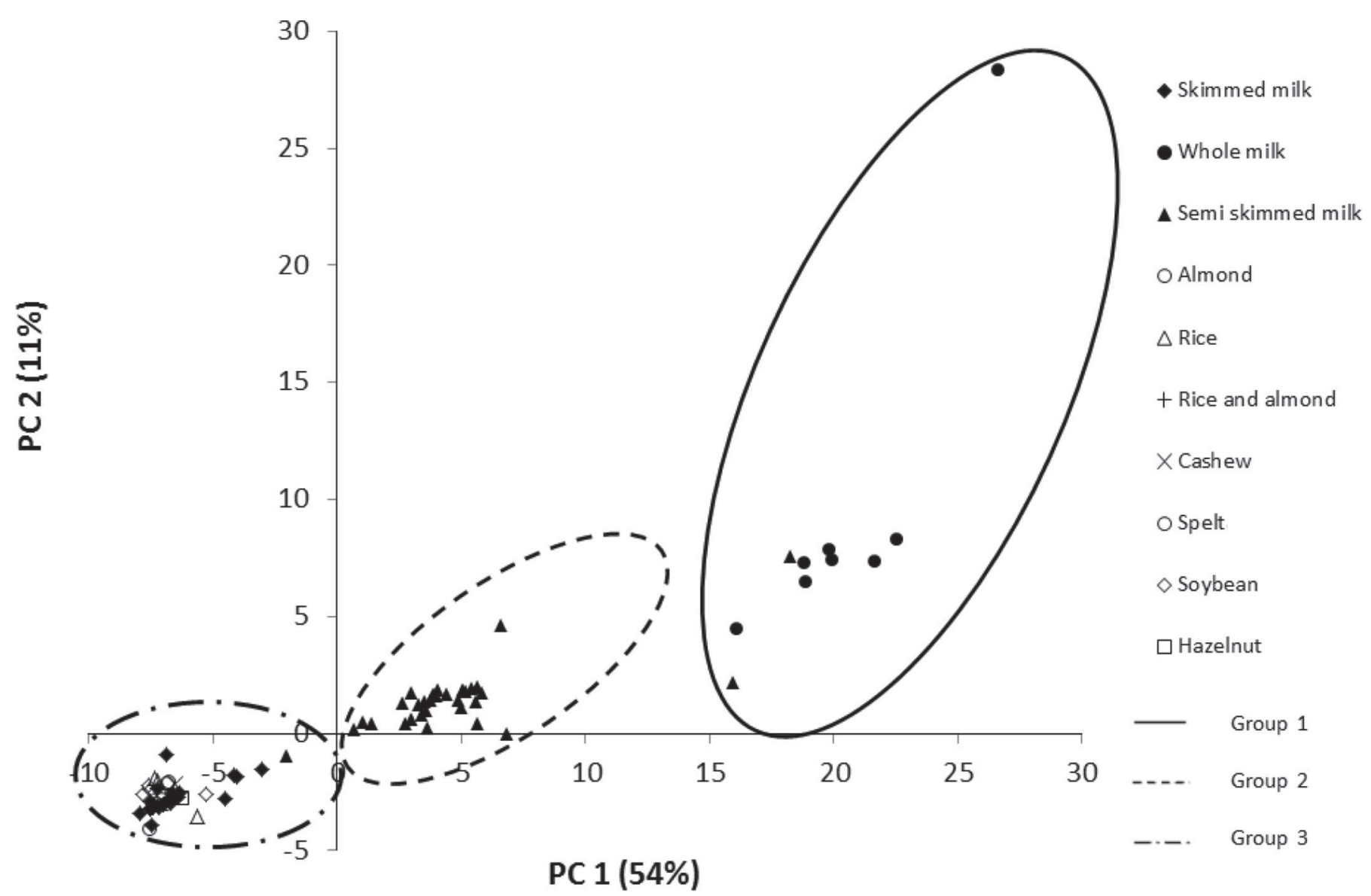

Figure 1. Principal component analysis (PC 1 vs. PC 2) for the fatty acid composition (g/L) of retail bovine milks ( $\mathrm{n}=62)$ and non-dairy beverages $(\mathrm{n}=27)$. 
depending on the raw material used to make them (Huth et al., 2015); thus, detailed labeling is advised for consumer information.

In summary, a multivariate chemometric approach enabled the differentiation of retail bovine milk (whole, semi-skim, and skim milks) and non-dairy beverages using their FA profile. Whole milk samples were clearly differentiated by SFA (C4:0, C6:0, C8:0, C12:0, C14:0, C17:0, and C18:0) and MUFA (C14:1 cis-9, C16:1 cis-9, $\mathrm{C} 17: 1$ cis-9, and $\mathrm{C} 18: 1$ trans-11) that were characteristic of dairy milk fat. Semi-skim milks were differentiated not only by SFA and MUFA, but also by n-3 FA content (C20:3n-3, C20:5n-3, and C22:6n-3). Skim milk and non-dairy beverages were not differentiated, possibly because of their similar C20 (C20:3n-6, C20:3n-3, and $\mathrm{C} 20: 5 n-3)$ and $\mathrm{C} 18: 2$ trans-9,trans-12 contents, as observed in PC2 and PC3, respectively. This chemometric method could be applied routinely in monitoring and control laboratories, and our FA profiling would be useful for nutritional guidelines, to increase consumption of certain foods with specific FA compositions or to design new dairy products.

\section{ACKNOWLEDGMENTS}

This study was supported by Fondo Nacional de Desarrollo Científico y Tecnológico (Chile; FONDECYT 11121142), Vicerrectoría de Investigación-Pontificia Universidad Católica de Chile (Proyecto Puente P1608), and the program: Consolidación del Programa de Inocuidad y Calidad de Alimentos de la Facultad de Agronomía e Ingeniería Forestal de la Pontificia Universidad Católica de Chile; como una estrategia para mejorar las herramientas de competitividad del sector alimentario (VCE4000011), as part of the Programa de Calidad e Inocuidad de los Alimentos (PCIA). Pilar Gómez-Cortés gratefully acknowledges the Spanish Ministry of Economy \& Competitiveness for the Juan de la Cierva research contract.

\section{REFERENCES}

Azcarate, S. M., R. Gil, P. Smichowski, M. Savio, and J. M. Camiña. 2017. Chemometric application in foodomics: Nutritional quality parameters evaluation in milk-based infant formula. Microchem. J. 130:1-6.

Bligh, E. G., and W. J. Dyer. 1959. A rapid method of total lipid extraction and purification. Can. J. Biochem. Physiol. 37:911-917.

Christie, W. W. 1982. A simple procedure for rapid transmethylation of glycerolipids and cholesteryl esters. J. Lipid Res. 23:1072-1075.
Chung, I. M., J. K. Kim, I. Park, J. Y. Oh, and S. H. Kim. 2016. Effects of milk type, production month, and brand on fatty acid composition: A case study in Korea. Food Chem. 196:138-147.

Eilander, A., R. K. Harika, and P. L. Zock. 2015. Intake and sources of dietary fatty acids in Europe: Are current population intakes of fats aligned with dietary recommendations? Eur. J. Lipid Sci. Technol. 117:1370-1377.

Fauquant, C., V. Briard, N. Leconte, and M. C. Michalski. 2005. Differently sized native milk fat globules separated by microfiltration: Fatty acid composition of the milk fat globule membrane and triglyceride core. Eur. J. Lipid Sci. Technol. 107:80-86.

Green, B. P., L. Turner, E. Stevenson, and P. L. S. Rumbold. 2015. Short communication: Patterns of dairy consumption in free-living children and adolescents. J. Dairy Sci. 98:3701-3705.

Harris, W. S. 2008. The omega-3 index as a risk factor for coronary heart disease. Am. J. Clin. Nutr. 87:1997S-2002S

Haug, A., A. T. Høstmark, and O. M. Harstad. 2007. Bovine milk in human nutrition - a review. Lipids Health Dis. 6:25.

Huth, P. J., V. L. Fulgoni III, and B. T. Larson. 2015. A systematic review of high-oleic vegetable oil substitutions for other fats and oils on cardiovascular disease risk factors: Implications for novel high-oleic soybean oils. Adv. Nutr. 6:674-693.

IFCN Dairy Network. 2016. Long-term dairy outlook-The IFCN vision of the dairy world in 2025. IFCN Dairy Network, Kiel, Germany.

Kim, N. S., J. H. Lee, K. M. Han, J. W. Kim, S. Cho, and J. Kim. 2014. Discrimination of commercial cheeses from fatty acid profiles and phytosterol contents obtained by GC and PCA. Food Chem. 143:40-47.

Kliem, K. E., and K. J. Shingfield. 2016. Manipulation of milk fatty acid composition in lactating cows: Opportunities and challenges. Eur. J. Lipid Sci. Technol. 118:1661-1683.

Knothe, G., and R. O. Dunn. 2009. A comprehensive evaluation of the melting points of fatty acids and esters determined by differential scanning calorimetry. J. Am. Oil Chem. Soc. 86:843-856.

Li, Y. H., J. C. Reif, Y. S. Ma, H. L. Hong, Z. X. Liu, R. Z. Chang, and L. J. Qiu. 2015. Targeted association mapping demonstrating the complex molecular genetics of fatty acid formation in soybean. BMC Genomics 16:841.

O'Donnell-Megaro, A. M., D. M. Barbano, and D. E. Bauman. 2011. Survey of the fatty acid composition of retail milk in the United States including regional and seasonal variations. J. Dairy Sci. 94:59-65.

Prado, F. C., J. L. Parada, A. Pandey, and C. R. Soccol. 2008. Trends in non-dairy probiotic beverages. Food Res. Int. 41:111-123.

Rivera-Espinoza, Y., and Y. Gallardo-Navarro. 2010. Non-dairy probiotic products. Food Microbiol. 27:1-11.

Shin, E.-C., C. E. Hwang, B. W. Lee, H. T. Kim, J. M. Ko, I. Y. Baek, Y.-B. Lee, J. S. Choi, E. J. Cho, W. T. Seo, and K. M. Cho. 2012 Chemometric approach to fatty acid profiles in soybean cultivars by principal component analysis (PCA). Prev. Nutr. Food Sci. $17: 184-191$.

Uncu, A. T., A. O. Uncu, A. Frary, and S. Doganlar. 2017. Barcode DNA length polymorphisms vs fatty acid profiling for adulteration detection in olive oil. Food Chem. 221:1026-1033.

Vestland, T. L., O. Jacobsen, S. A. Sande, A. H. Myrset, and J. Klaveness. 2016. Characterization of omega-3 tablets. Food Chem. 197:496-502.

Visioli, F., and A. Strata. 2014. Milk, dairy products, and their functional effects in humans: A narrative review of recent evidence. Adv. Nutr. 5:131-143.

Yang, A., H. Smyth, M. Chaliha, and A. James. 2015. Sensory quality of soymilk and tofu from soybeans lacking lipoxygenases. Food Sci. Nutr. 4:207-215. 